\title{
PRISÃO EM FLAGRANTE: NOTAS ACERCA DA INVIOLABILIDADE DO DOMICÍLIO ANTE A SUSPEITA DE TRÁFICO DE DROGAS
}

Fabiana Vergílio Souto

Universidade do Oeste Paulista - UNOESTE, Curso de Direito. E-mail: fabianavergiliosouto@hotmail.com

\section{RESUMO}

A invasão de domicílio só pode ser efetuada em hipóteses expressamente previstas no ordenamento jurídico pátrio, dentre as quais, em casos flagrante delito. Em qualquer outra circunstância além das consubstanciadas na Constituição Federal, é vedado ao agente público, sem a concordância do morador, ingressar no domicílio, sob pena de, no âmbito processual, serem apreciadas como ilícitas as provas obtidas. A pesquisa objetivou analisar conceitos fundamentais acerca do tema - prisão em flagrante e inviolabilidade do domicílio - desenvolvendo a abordagem qualitativa até a exploração do caso concreto (Recurso Especial no 1.574.681-RS (2015/0307602-3). Coligiu-se que as medidas inerentes ao poder de polícia do Estado, no que concerne à prisão em flagrante e à violação domiciliar, são as previstas em lei, não devendo ser utilizadas além do estritamente necessário.

O método hipotético-dedutivo, por meio de pesquisa bibliográfica, viabiliza o estudo, considerando que explora, qualitativamente, o caso emblemático analisado, abordando a prisão em flagrante mediante violação de domicílio diante da suspeita de tráfico de drogas.

Para dar seguimento e fundamentação teórica, utilizou-se como principal mecanismo de investigação, a busca de material bibliográfico, mais especificamente livros escritos, e do formato digital, enfatizando as doutrinas e autores prestigiados, além de publicações e julgados disponibilizados digitalmente nos sites do Supremo Tribunal Federal e Superior Tribunal de Justiça.

Palavras-chave: Direitos Fundamentais. Prisão em flagrante. Tráfico de drogas. Domicílio.

\section{FLAGRANT PRISON: NOTES ABOUT INVIOLABILITY OF DOMICILE IN THE CRIME OF DRUG TRAFFIC}

\begin{abstract}
The home invasion can only be done expressly provided for assumptions in the Brazilian legal system, including, in cases of arrest in flagrante. In any other circumstance beyond those embodied in the Federal Constitution, it is forbidden to the public, without the consent of the resident, enter the domicile, otherwise, in the context of procedure be considered as illicit evidence obtained. The research aimed to analyze fundamental concepts about the theme-arrest in flagrante and inviolability of domicile developing the qualitative approach to the exploitation of the case. Also edited measures inherent to the police power of the State, regarding the arrest in flagrante and violating house arrest, are those provided for by law, and should not be used beyond what is strictly necessary.

The hypothetical-deductive method, by means of bibliographical research, makes the study, whereas explores, qualitatively, the emblematic case reviewed, addressing the arrest in flagrante by breaking and entering on suspicion of trafficking in drugs. To follow up and theoretical foundation, it was used as the main mechanism for investigation, the search for bibliographical material, namely books, and digital format, emphasizing the doctrines and prestigious authors, in addition to publications and judged digitally in sites available Supreme Court and Superior Court of Justice.
\end{abstract}

Keywords: Fundamental Rights. Flagrant prison. Drug trafficking. Domicile. 


\section{INTRODUÇÃO}

No intuito de combater o tráfico de drogas, eventualmente os agentes públicos incorrem em arbitrariedades.

Dentre as arbitrariedades cometidas pelos representantes do Estado, a invasão de domicílio em comunidades carentes é muito comum apesar das restrições impostas por lei.

Com o intuito de proteger grupos sociais vulneráveis em relação às comuns arbitrariedades praticadas em atividades policiais, os Tribunais Superiores têm proferido decisões que tutelam a inviolabilidade domiciliar, pois, apesar de constituir um direito fundamental juridicamente previsto, tal garantia é frequentemente depreciada. ${ }^{1}$

\section{PRISÃO-PENA E PRISÃO PROCESSUAL}

A prisão é a privação da liberdade de locomoção, é a condenação ao encarceramento, que pode vir por meio de uma decisão condenatória transitada em julgado ou não (TÁVORA, 2019, p. 1).

A prisão pode ser denominada como prisão-pena, sendo esta imposta por meio de sentença condenatória transitada em julgado, ou seja, em razão da privação da liberdade com o intuito de executar decisão judicial (CAPEZ, 2013).

Não tem finalidade acautelatória, tampouco processual, tendo em vista que se trata de medida penal destinada à satisfação da pretensão executória do Estado.

Rangel (2018) destaca: "Deve-se considerar a imprescindível incidência do princípio da proporcionalidade - sempre conectado que está ao valor dignidade da pessoa humana - quando da aplicação da prisão cautelar".

Em regra, por meio do mandado de prisão que se viabiliza a restrição da liberdade, porém, há hipótese na qual será dispensado o documento em questão (TÁVORA, 2019, p. 1).

Seguindo em sentido oposto à prisãopena, surge a prisão sem pena ou processual, sendo esta de natureza estritamente processual e de finalidade cautelar, visando assegurar o bom andamento da investigação criminal, do processo penal ou da futura execução da pena. Depende

\footnotetext{
${ }^{1}$ Art. 11.2 da Convenção Americana de Direitos Humano: Ninguém pode ser objeto de ingerências arbitrárias ou abusivas em sua vida privada, em sua família, em seu domicílio ou em sua correspondência, nem de ofensas ilegais à sua honra ou reputação.
}

do periculum in mora e do fumus boni iuris. É aplicável aos casos em que é impossível aguardar o término no processo para privar o agente de sua liberdade, tendo em vista que a demora pode permitir que solto, o sujeito continue praticando crimes, atrapalhe a produção de provas ou simplesmente desapareça (CAPEZ, 2013).

De acordo com Tourinho Filho (2007, p. 445): "Tratando-se, como se trata, de providência cautelar, indispensável a coexistência dos dois pressupostos: fumus boni juris e periculum libertatis, mesmo porque medida cautelar não há que dispense sua conglomeração".

Há três modalidades de prisão processual: prisão em flagrante, prisão preventiva e prisão temporária, porém, para o conciso estudo, convém versar somente sobre a prisão em flagrante.

\section{A PRISÃO EM FLAGRANTE}

Na doutrina, Renato Brasileiro de Lima (2011, p. 177) define:
A expressão "flagrante" deriva do latim "flagrare" (queimar), e "flagrans", "flagrantis" (ardente, brilhante, resplandecente), que no léxico, significa acalorado, evidente, notório, visível, manifesto. Em linguagem jurídica, flagrante seria uma característica do delito, é a infração que está queimando, ou seja, que está sendo cometida ou acabou de sê-lo, autorizando-se a prisão do agente mesmo sem autorização judicial em virtude da certeza visual do crime. Funciona, pois, como mecanismo de autodefesa da sociedade.

A prisão em flagrante pode ser definida como um mecanismo de autodefesa da sociedade, consubstanciada na privação de liberdade e locomoção daquele que é surpreendido durante o ato ou na pós-execução da infração penal.

Ainda no entendimento do prestigiado doutrinador supracitado, ipsis verbis:

Sem embargo de opiniões em contrário, pensamos 
que a prisão em flagrante tem caráter precautelar. Não se trata de uma medida cautelar de natureza pessoal, mas sim precautelar, porquanto não se dirige a garantir o resultado final do processo, mas apenas objetiva colocar o capturado à disposição do juiz para que adote uma verdadeira medida cautelar (LIMA, 2011, p. 182).

Quando há situação de flagrante ${ }^{2}$, o agente é preso sem a necessidade de prévio mandado judicial, conforme o art. $5^{\circ}$, inciso LXI da Constituição Federal: "Ninguém será preso senão em flagrante delito ou por ordem escrita e fundamentada de autoridade judiciária competente, salvo nos casos de transgressão militar ou crime propriamente militar, definidos em lei".

Parafraseando Renato Brasileiro de Lima (2017, p. 927), a prisão em flagrante funciona como mero ato administrativo dispensa autorização judicial e exige apenas a aparência de tipicidade, sem a valoração acerca da ilicitude e culpabilidade.

A doutrina conceitua diferentes modalidades do flagrante, considerando o contexto em que este se dá:

Flagrante próprio é aquele que o agente é surpreendido executando o tipo penal ou é encontrado após a consumação criminal. Conforme mencionado, trata-se de situação em que o sujeito é visto durante a realização dos atos executórios da infração penal ou colaborando para sua concretização (REIS; GONÇALVES, 2017, p. 389).

Flagrante impróprio, quando o agente é perseguido logo após cometer 0 ato ilícito, fazendo-se presumir que o mesmo seja o autor do crime (CAPEZ, 2013).

Flagrante presumido ou ficto, quando o agente é preso por possuir objetos que tenham

\footnotetext{
${ }^{2}$ Art. 302 do Código de Processo Penal - Considera-se em flagrante delito quem:

I - está cometendo a infração penal;

II - acaba de cometê-la;

III - é perseguido, logo após, pela autoridade, pelo ofendido ou por qualquer pessoa, em situação que faça presumir ser autor da infração;

IV - é encontrado, logo depois, com instrumentos, armas, objetos ou papéis que façam presumir ser ele autor da infração.
}

sido utilizados como instrumentos para a execução do tipo penal, fazendo presumir que este seja o autor da infração, assim, o sujeito não é perseguido, mas localizado, ainda que casualmente, na posse das coisas mencionadas na lei, de modo que a situação fática leve à conclusão de que ele é autor do delito (REIS; GONÇALVES, 2017, p. 391).

Flagrante compulsório ou obrigatório, ganha tal denominação tendo em vista a obrigação que as autoridades policiais têm de realizar o cerceamento da liberdade, nos casos que ocorreram flagrante próprio, impróprio e presumido.

Ao ter ciência de um crime em flagrante a autoridade policial tem o dever de agir, a omissão pode cominar em responsabilidade criminal se for comprovado que agiu para satisfazer interesse ou sentimento pessoal.

Flagrante facultativo é aquele que pessoa comum do povo presenciou o flagrante e dispõe da faculdade de realizar ou não a prisão, sendo este fundamentado pelo artigo 301 do Código de Processo Penal ${ }^{3}$.

Flagrante preparado ou provocado ${ }^{4}$, "ocorre como crime putativo por obra do agente provocador, quando alguém de forma insidiosa provoca o agente a prática de um crime, ao mesmo tempo em que toma providências para que não se consume" (JESUS, 1981, p. 160 apud CAPEZ, 2013).

Pondera-se o entendimento, nesse caso, de que o flagrante não existe, ou seja, o sujeito não pode ser preso após ser seduzido pela prática criminal preparada por autoridades policiais, vejamos: "Não há flagrante preparado quando a ação policial aguarda o momento da prática delituosa, valendo-se de investigação anterior, para efetivar a prisão, sem utilização de agente provocador" (RSTJ, 10/389).

Há exceção quando se trata de tráfico de drogas, visto que, apesar do agente ter sido induzido a vender a droga, o crime não se materializa apenas com $\mathrm{o}$ ato da venda de substância entorpecente, afigurando-se como possível que o agente responda pelo crime de tráfico nas modalidades trazer consigo guardar, oferecer e ter em depósito, dentre os demais verbos nucleares do tipo penal.

\footnotetext{
${ }^{3}$ Art. 301 do Código de Processo Penal - Qualquer do povo poderá e as autoridades policiais e seus agentes deverão prender quem quer que seja encontrado em flagrante delito.

${ }^{4}$ Súmula 145 do STF, verbis: Não há crime quando a preparação do flagrante pela polícia torna impossível a sua consumação.
} 
Flagrante retardado, na presente hipótese, o agente policial deixa de efetuar a prisão em flagrante, pois pretende acompanhar mais de perto a organização criminosa para chegar até os demais membros, podendo ser realizada somente em casos de crime organizado.

Salienta-se, ante os breves apontamentos doutrinários supramencionados, que o princípio constitucional da presunção de inocência, segundo o qual ninguém será considerado culpado até o trânsito em julgado de sentença penal condenatória (art. 5ㅇ, LVII, da CF), não impede a decretação da prisão processual, uma vez que a própria Constituição, em seu art. 5ㅇ, LXI, prevê a possibilidade de prisão em flagrante ou por ordem escrita e fundamentada do juiz competente (REIS; GONÇALVES, p. 387, 2017).

\section{HIPÓTESES DE RELAXAMENTO DA PRISÃO EM FLAGRANTE}

O art. 50, LVX da Constituição Federal dispõe que "a prisão ilegal será imediatamente relaxada pela autoridade judiciária". 0 dispositivo em questão visa tutelar a liberdade de locomoção nos casos que a prisão tenha sido executada de maneira ilegal (LIMA, 2017, p. 919).

A ilegalidade da prisão conspurca a custódia e pode ser identificada no início do ato de constrição de liberdade ou durante o seu curso, o vício em questão tem como resultado o relaxamento da prisão, que significa o reconhecimento da ilegalidade da restrição imposta (LIMA, 2017, p. 919).

No que tange a prisão em flagrante, só será legítima se não houver vícios, devendo ser relaxada em casos de flagrante preparado, forjado ou quando a lavratura da prisão é feita sem as formalidades expressas em lei.

O intuito principal da prisão em flagrante é evitar a fuga do infrator e auxiliar na colheita de elementos informativos. Quando a prisão é feita em flagrante, há mais êxito na colheita de elementos de informações, fato que auxilia na comprovação do fato delituoso em juízo. Outra finalidade é a preservação da identidade física do preso no caso de crimes que causam comoção pública evitando-se um possível linchamento (LIMA, 2017).

Sendo a liberdade regra, e o cerceamento exceção, a prisão em flagrante tem como escopo evitar a fuga do autor do fato, resguardar a sociedade, dando-lhe confiança na lei, servir de exemplo para aqueles que desafiam a ordem jurídica e proteger as provas que, por ventura, serão colhidas no curso do inquérito policial ou na instrução criminal quanto à materialidade e autoria do delito (RANGEL, 2018).

A prisão em flagrante, durante muito tempo era motivo suficiente para que o agente ficasse preso por tempo indeterminado, enquanto durasse o processo. Foi apenas no final da década de 70 (setenta), mais precisamente no ano de 1977, com a Lei no 6.416/77 que fora inserido o parágrafo único do artigo 310 , que dispõe acerca do recebimento da cópia do auto de prisão ao magistrado, através disso, o magistrado é obrigado a examinar a legalidade da medida com o intuito de determinar um possível relaxamento e também verificar alguns dos motivos que autorizam a decretação de prisão preventiva (LIMA, 2017).

O magistrado ao receber o auto de prisão, poderá relaxá-la ou poderá convertê-la em preventiva. Nos casos em que for concedida a liberdade provisória, com ou sem fiança, o magistrado poderá requisitar o comparecimento a todos os atos processuais, sob pena de revogação da medida.

Cogita-se a seguinte hipótese: um indivíduo, parado defronte a sua residência, ao avistar policiais passando na rua, corre para dentro da residência. Os agentes públicos, policiais, consideram tal atitude suspeita, invadem a casa do cidadão, encontram drogas em quantidade e contexto suficientes para ser considerado tráfico de drogas.

Foram encontrados indícios de autoria e materialidade do crime de tráfico de drogas ao passo que a Constituição Federal considera o domicílio asilo inviolável, mas permite a invasão domiciliar em flagrante delito.

O Superior Tribunal de Justiça prolatou uma decisão que divide opiniões e a situação ocorreu exatamente da forma supracitada. Tratase do Recurso Especial no 1.574.681-RS (2015/0307602-3) .

Antes de analisar o caso em questão e entender todas as razões para a ocorrência do relaxamento segundo o Superior Tribunal de Justiça, cabe entender as hipóteses admitidas

\footnotetext{
${ }^{5}$ Ementa do Recurso Especial no 1.574.681-RS (2015/0307602-3): RECURSO ESPECIAL. TRÁFICO DE DROGAS. FLAGRANTE. DOMICÍLIO COMO EXPRESSÃO DO DIREITO À INTIMIDADE. ASILO INVIOLÁVEL. EXCEÇÕES CONSTITUCIONAIS. INTERPRETAÇÃO RESTRITIVA. INVASÃO DE DOMICÍLIO PELA POLÍCIA. NECESSIDADE DE JUSTA CAUSA. NULIDADE DAS PROVAS OBTIDAS. TEORIA DOS FRUTOS DA ÁRVORE ENVENENADA. ABSOLVIÇÃO DO AGENTE. RECURSO NÃO PROVIDO.
} 
pela Constituição Federal de 1988, no que tange a invasão de domicílio.

\section{DAS HIPÓTESES DE INVASÃO DE DOMICÍLIO}

$\mathrm{O}$ art. 5ㅇ, XI da Constituição Federal consagra o direito do indivíduo ao aconchego do lar com sua família, definindo-a como asilo inviolável do indivíduo. Assim, a Constituição proíbe que haja a penetração em residência alheia sem que haja o consentimento do morador, exceto nos casos de flagrante delito, ou desastre, ou para prestar socorro, ou, durante o dia, por determinação judicial.

O Plenário do Supremo Tribunal Federal concluiu no julgamento do RE 603616:

A entrada forçada em
domicílio sem mandado
judicial só é lícita, mesmo
em período noturno,
quando aparada em
fundadas razões
devidamente justificadas a
posteriori, que indiquem
que dentro da casa ocorre
situação de flagrante
delito, sob pena de
responsabilidade
disciplinar, civil e penal do
agente ou da autoridade e
da nulidade dos atos
praticados.

A inviolabilidade de domicílio é um direito de primeira geração, ou seja, foi a primeira conquista libertária do ser humano reconhecido por meio de uma Constituição. Os direitos de primeira geração caracterizam a

\footnotetext{
${ }^{6}$ Art. 245 do Código de Processo Penal: As buscas domiciliares serão executadas de dia, salvo se o morador consentir que se realizem à noite, e, antes de penetrarem na casa, os executores mostrarão e lerão o mandado ao morador, ou a quem o represente, intimandoo, em seguida, a abrir a porta.

$\S 1$ 은 Se a própria autoridade der a busca, declarará previamente sua qualidade e o objeto da diligência.

$\S 2$ 으 caso de desobediência, será arrombada a porta e forçada a entrada.

$\S 3$ 3 Recalcitrando o morador, será permitido o emprego de força contra coisas existentes no interior da casa, para o descobrimento do que se procura.

$\S 4$ ㅇ Observar-se-á o disposto nos $\S \S 2$ e 3으, quando ausentes os moradores, devendo, neste caso, ser intimado a assistir à diligência qualquer vizinho, se houver e estiver presente.

$\S 5$ o Se é determinada a pessoa ou coisa que se vai procurar, o morador será intimado a mostrá-la.

$\S 6$ 0 Descoberta a pessoa ou coisa que se procura, será

imediatamente apreendida e posta sob custódia da autoridade ou de seus agentes.

$\S 7$ ㅇ Finda a diligência, os executores lavrarão auto circunstanciado, assinando-o com duas testemunhas presenciais, sem prejuízo do disposto no $\S 4$ ㅇ․
}

primária ideia de Estado de Direito, ou seja, um Estado submisso a um texto legal, no qual a lei é soberana, estando todos os governantes sujeitos as atribuições consagradas em lei (ARAÚJO; NUNES, 2001, p. 81).

Os direitos de primeira geração também são denominados como direitos civis, individuais e políticos, são direitos de defesa do indivíduo contra a arbitrariedade estatal, cuja preocupação é definir uma área de atuação do Poder Público em simultaneidade com a reserva de espaço de atuação do indivíduo, uma política de afastamento do Estado das relações individuais e sociais. O Estado sustenta apenas a figura de guardião da liberdade, permanecendo longe de qualquer tipo de relacionamento social (ARAÚJO; NUNES, 2001, p. 81).

Partindo do pressuposto de que o Estado tutela a privacidade no domicílio, cabe estabelecer algumas definições para domicílio.

Uma das definições encontra-se no Código Civil, que o caracteriza como residência com ânimo definitivo. Já a Constituição ao mencionar a palavra domicílio parece querer nos levar a imaginar um ambiente mais intimista e privativo, podendo ser considerado para tal fim até mesmo a residência ocasional (RANGEL, 2018).

Deste modo, o direito à inviolabilidade domiciliar está ligado ao direito à intimidade e à privacidade, assim sendo, mesmo na residência ocasional, local de habitação coletiva, local de trabalho que não seja acessível ao público, devem ser considerados como domicílio para fins constitucionais, o que obviamente veda a entrada arbitrária de agentes administrativos como a polícia fora das hipóteses taxativas enunciadas no texto constitucional: como mandado judicial e flagrante delito (NUCCl, 2017, p. 758).

Cabe elucidar que, no caso em análise, o sujeito preso estava na frente de sua residência, e ao avistar a viatura policial, correu para dentro. A atitude em questão não pode ser tomada como criminosa, restando claro que não há fundamentação suficiente para a inviolabilidade domiciliar. 


\section{DECISÃO DO STJ ACERCA DA INVIOLABILIDADE DE DOMICÍLIO SEM INDÍCIOS DE AUTORIA E MATERIALIDADE DO DELITO}

No julgamento do Recurso Especial no 1.574.681-RS (2015/0307602-3) ${ }^{7}$, o Superior Tribunal de Justiça afirmou que, na hipótese em exame, o indivíduo estava em local supostamente conhecido como ponto de comércio de entorpecentes e que ao avisar a viatura policial correu para sua residência. As autoridades policiais acharam tal atitude suspeita no momento e decidiram violar o domicílio, no qual foram encontradas substâncias entorpecentes em quantidade suficiente para haver a suspeita de eventual tráfico de drogas (STJ, 2017).

A Suprema Corte definiu que a entrada forçada em domicílio sem mandado judicial só será legítima a qualquer hora do dia, inclusive durante a noite quando houver razões justificadas. Pelas atitudes analisadas no caso concreto não houve indícios de estar ocorrendo na residência uma veemente situação de flagrante delito (STJ, 2017).

No julgado, ipsis litteris:

0 fato de alguém retirarse para dentro de casa ao avistar uma guarnição PM não constitui crime nem legitima a perseguição ou a prisão, menos ainda a busca nessa casa, por não ser suficientemente indicativo de algum crime em curso, a par de ser pouco crível, pois é de esperar que tais suspeitos tentem tomar distância do que possa incriminá-los. Com efeito, a busca domiciliar e pessoal do réu, que se encontrava dentro de casa, não estava autorizada e não podia ser realizada (STJ, 2017).

A Corte entende a necessidade da tomada urgente de decisões por parte dos policiais, porém, durante a ação, pessoas são submetidas a situações abusivas e arbitrárias,

\footnotetext{
${ }^{7} \mathrm{O}$ recorrido foi condenado, em primeiro grau, à pena de 4 anos e 2 meses de reclusão, em regime inicial semiaberto, mais multa, pela prática do crime previsto no art. 33, caput, e $\S 4$ 으, da Lei n.

11.343/2006. A defesa, então, interpôs apelação ao Tribunal de origem, havendo sido dado provimento ao recurso, para absolver o acusado, com fundamento no art. 386, II, do Código de Processo Penal.
}

principalmente quando são socialmente vulneráveis e de baixa renda, pelas mesmas palavras do Ministro Relator:

A complexa e sofrida realidade social brasileira sujeita as forças policiais a situações de risco e à necessidade de tomada urgente de decisões no desempenho de suas relevantes funções, o que há de ser considerado quando, no conforto de seus gabinetes, realizamos os juízes o controle posterior das ações policiais. Mas, não se há de desconsiderar, por outra ótica, que ocasionalmente a ação policial submete pessoas a situações abusivas e arbitrárias, especialmente as que habitam comunidades socialmente vulneráveis e de baixa renda (STJ, 2017).

Prossegue o Ministro Relator:

[...] para legitimar-se o ingresso em domicílio alheio, é necessário tenha a autoridade policial fundadas razões para acreditar, com lastro em circunstâncias objetivas, no atual ou iminente cometimento de crime no local onde a diligência vai ser cumprida, e não mera desconfiança fulcrada, v.g., na fuga de indivíduo de uma ronda policial, comportamento que pode ser atribuído a várias causas que não, necessariamente, a de estar o abordado portando ou comercializando substância entorpecente (STJ, 2017).

Quanto ao contexto fático, in verbis: Consta dos autos que o acusado estava em local supostamente conhecido como ponto de venda de 
drogas, quando, ao avistar a guarnição de policiais, empreendeu fuga para dentro de sua casa, sendo certo que, após revista em seu domicílio, foram encontradas substâncias entorpecentes (18 pedras de crack). Veja-se, portanto, que havia somente vagas suspeitas sobre eventual tráfico de drogas perpetrado pelo réu, em razão, única e exclusivamente, do local em que ele estava no momento em que policiais militares realizavam patrulhamento de rotina, - que fez surgir a desconfiança de que estaria traficando substâncias

entorpecentes. Não há referência à prévia investigação, monitoramento ou campanas no local. Não há, da mesma forma, nenhuma menção a qualquer atitude suspeita, externalizada em atos concretos, tampouco movimentação de pessoas típica de comercialização de drogas. Também não se tratava de averiguação de denúncia robusta e atual acerca da ocorrência de tráfico naquele local. Há apenas a descrição de que, quando o réu avistou os policiais militares, correu para dentro de sua residência, onde foi abordado. Aliás, a própria concentração fáticotemporal dos acontecimentos - tudo se passou muito próximo e muito rápido - torna inclusive duvidosa eventual caracterização de "fuga" (STJ, 2017).

A ausência de justificativas e de elementos seguros a legitimar a ação dos agentes públicos diante da discricionariedade concedida às autoridades policiais relativa à identificação de situações suspeitas atinentes ao tráfico de drogas pode violar o direito à intimidade e à inviolabilidade domiciliar (STJ, 2017).

No entendimento de Rangel (2018): “[...] as medidas inerentes ao poder de polícia do Estado são as previstas em lei (devido processo legal), não devendo ser utilizadas além do estritamente necessário".

Em relação à permanência, característica do tipo penal em análise, pondera-se:

Especificamente em relação ao estado de flagrância - cujas situações previstas no Código de Processo Penal são explicitadas e distinguidas por circunstâncias espaçotemporais (art. 302) e pela natureza do crime (sendo permanente, como na hipótese do tráfico de entorpecente, "entendese o agente em flagrante delito enquanto não cessar a permanência", conforme art. 303) -, é necessário perscrutar as circunstâncias concretas de cada caso, que permitam aferir, em última análise, a legalidade do próprio procedimento policial que subjaz à possível prisão do agente e lavratura do respectivo auto flagrancial. (STJ, 2017)

[...] O fato de, nos crimes como o tráfico de drogas, o estado de flagrância se protrair no tempo - o que, diga-se, dogmaticamente correto não significa concluir que a vaga suspeita de prática desse delito legitima a mitigação do direito à inviolabilidade de domicílio. A fundada suspeita precisa ampararse em elementos objetivos, afastando nuances subjetivas, de sorte a não permitir que se ocupe o policial de preocupar-se com a pessoa de quem ele 
identifica, a priori, como "o traficante", e reserve sua atividade para apurar "condutas e atos", indicativas da prática de um crime. (STJ, 2017)

Os cidadãos fragilizados economicamente têm o direito de sentirem-se seguros e ver preservados seus mínimos direitos constitucionais, o que incluí não ter a residência invadida a qualquer momento por policiais sem as devidas formalidades legais (STJ, 2017, p. 2).

A Corte ainda afirma que não pretende transformar o domicílio em abrigo para criminosos, todavia, adentrar o domicílio alheio só deve ser permitido diante de situação fática emergencial consubstanciada em flagrante delito (STJ, 2017).

Portanto, pelo contexto fático delineado nos autos, em que pese eventual boa-fé dos policiais militares, entendo que não havia elementos objetivos e racionais que justificassem a invasão de domicílio. Eis a razão pela qual, dado que a casa é asilo inviolável do indivíduo, desautorizado estava 0 ingresso na residência do recorrido, de maneira que as provas obtidas por meio da medida invasiva são ilícitas, bem como todas as que delas decorreram, tal como decidiu o acórdão recorrido, ao concluir pela absolvição do recorrido "por ausência de prova da materialidade do crime imputado" (STJ, 2017).

De acordo com o entendimento do Superior Tribunal de Justiça, não há que se considerar lícita a violação do domicílio, visto que nenhuma diligência anterior indicava que na residência ocorria o tráfico de drogas. Os policiais, ao violarem o domicílio, agiram de forma meramente intuitiva, sem ato ou fato palpável que justificasse a violação de tão importante garantia constitucionalmente protegida.

\section{CONCLUSÃO}

Ante o exposto, observa-se que a prisão em flagrante pode ser efetuada tanto pelas autoridades policiais como também pelas pessoas comuns do povo, desde que se enquadre nas hipóteses tipificadas em lei.

No que tange a invasão de domicílio, só poderá ser realizada quando houver veementes indícios de ação criminosa naquele local.

Caso haja a invasão domiciliar injustificada e sejam encontrados possíveis indícios de materialidade e autoria, via de regra, não poderão ser utilizados como meio de prova no processo, tendo em vista que estarão contaminados pela ilegalidade.

Além da inutilização das provas colhidas por meios ilegítimos, a prisão em flagrante deverá ser imediatamente relaxada.

Apesar da decisão do Superior Tribunal de Justiça causar polêmica, esta é justificada por preceito basilar constitucional que determina o domicílio como asilo inviolável, no art. 5ㅇ, XI.

Diante das circunstâncias fáticas e jurídicas, constata-se que a entrada em domicílio sobre o qual recaia a suspeita de tráfico de drogas deve se fundamentar em informações objetivas da prática do crime, não em meras suposições sobre atividade delituosa.

Destarte, a decisão em questão não visa dar asilo aos criminosos, mas proteger toda e qualquer pessoa, e evitar que domicílios sejam violados sem indícios preexistentes de atividade criminosa, dessa forma coibindo a arbitrariedade policial, para que estes ajam sempre estritamente nos limites legais no exercício da função, visto que na esfera processual penal, o direito à inviolabilidade de domicílio tangencia o contexto probatório, ressoando sobre a própria validade das provas ou mesmo dos procedimentos probatórios.

\section{REFERÊNCIAS}

ARAÚJO, Luiz Alberto David; NUNES JUNIOR, Vidal Serrano. Curso de Direito Constitucional. 5. ed. São Paulo: Saraiva, 2001.

BRASIL. Constituição (1988). Constituição da República Federativa do Brasil. Brasilia, DF: Senado Federal, 1988.

CAPEZ, Fernando. Curso de processo penal. 20. ed. São Paulo: Saraiva, 2013. 
LIMA, Renato Brasileiro de. Manual de processo penal. 5. ed. Salvador: Editora Podivm, 2017.

LIMA, Renato Brasileiro de. Nova prisão cautelar: doutrina, jurisprudência e prática. Niterói: Impetus, 2011.

NUCCl, Guilherme de Souza. Código de Processo Penal comentado. 16. ed. Rio de Janeiro: Forense, 2017.

RANGeL, Paulo. Direito Processual Penal. 26. ed. São Paulo: Atlas, 2018.

REIS, Alexandre Araújo, GONÇALVES, Victor Rios. Direito processual penal esquematizado. 6. ed. São Paulo: Saraiva, 2017.

STJ. SUPERIOR TRIBUNAL DE JUSTIÇA. Recurso Especial: № Resp:1.574.681RS2015/0307602-3. Relator: Rogério Schietti Cruz. DJ:24/04/2017. Brasília, 2017. Disponível em: https://ww2.stj.jus.br/processo/revista/documen to/mediado/?componente=ITA\&sequencial $=1575$ 162\&num_registro $=201503076023 \&$ data $=20170$ 530\&formato=PDF. Acesso em: 14 de abr. 2019.

TOURINHO FILHO, Fernando Costa. Processo Penal. 29. ed. São Paulo: Saraiva, 2007. 